\title{
The Exotic Plants of Indonesia: Mahkota Dewa (Phaleria macrocarpa), Sikaduduak (Melastoma malabathricum Linn) and Mengkudu (Morinda citrifolia) as Potent Antioxidant Sources
}

\author{
Tuty Anggraini", Paul Lewandowsky * \\ \# Faculty of Agriculture Technology Andalas University Kampus Limau Manis, West Sumatra, Indonesia \\ E-mail: tuty_anggraini@yahoo.co.id
}

* School of Medicine Deakin University 75 Pigdons Road Waurn Ponds 321, Australia

\begin{abstract}
The present study aims to determine the antioxidant activity of of three unique plants from Indonesia used for medicine of dried and etahnolic extract. Plants that are commonly used as medicine is Phaleria macrocarpa known as mahkota dewa (In West Sumatra), Melastoma malabathricum known as sikaduduak and Morinda citrifolia known as mengkudu. The DPPH methods used to the antioxidant assay. The dried Melastoma malabathricum dried and ethanolic extract shows the highest antioxidant activity than Phaleria macrocarpa and Morinda citrifolia both powder and ethanolic extract. Started from $0,125 \mathrm{mg} / \mathrm{L}$ for $\mathrm{PMm}$ and $0,25 \mathrm{mg} / \mathrm{L}$ for PPm can be used for antioxidant measurement with DPPH.
\end{abstract}

Keywords-Phaleria macrocarpa, Morinda citrifolia, Melastoma malabathricum, antioxidant.

\section{INTRODUCTION}

Oxidation is an important reaction that produces free radicals in food, chemicals, and even in living systems. Free radicals have an important role in processes of food spoilage and chemical materials degradation and they also contribute to more than 100 disorders in humans [1]. Antioxidants are defined as substances that even at low concentration significantly prevent oxidation of easy oxidisable substrates [2]. Free radicals are molecules or atoms with an unpaired electron. The unpaired electron results in a high level of reactivity because the free radical 'seeks' another electron to fulfil a pair. Free radicals are a natural by-product of cellular metabolism, but are also generated by the external action of ultraviolet radiation, toxic substances, ozone, cigarette smoke, microbial attacks, and even intensive exercise [3]. It is generally accepted that free radicals play an important role in the development of tissue damage and pathological events in living organisms. Reactive oxygen species (ROS) have deleterious effects on cellular membranes and internal structures that might contribute to the onset of cardiovascular disease, cancer, and impairment of the immune function by altering the metabolism [4].

Antioxidants are used to retard the reaction of organic materials, such as synthetic polymers, with atmospheric oxygen. This reaction can cause the following: degradation of the mechanical, aesthetic, and electrical properties of polymers; loss of flavor and development of rancidity in foods; and increase in the viscosity, acidity, and formation of insolubles in lubricants. The need for antioxidants depends upon the chemical composition of the substrate and the conditions of exposure [5]. Oxidation may be inhibited by various methods including prevention of oxygen access, use of lower temperature, inactivation of enzymes catalyzing oxidation, reduction of oxygen pressure, and the use of suitable packing. Another method of protection against oxidation is to use specific additives that inhibit oxidation. These are correctly called oxidation inhibitors, but today are generally called antioxidants. Antioxidants can inhibit oxidation in two ways: either by scavenging free radicals, in which case the compounds are called primary antioxidants, or by a mechanism that does not involve direct scavenging of free radicals, in which case the compounds are called secondary antioxidants. Primary antioxidants include phenolic compounds such as vitamin E ( $\alpha$-tocopherol). Secondary antioxidants operate by a variety of mechanisms including binding of metal ions, scavenging oxygen, converting hydroperoxides to non-radical species, absorbing UV radiation, and deactivating singlet oxygen [6].

Indonesia is a tropical country that has many species that can be used as medicine. West Sumatra is also one particular area that has a variety of plant species used as traditional 
medicine community. Among the plants that are commonly used as medicine is Phaleria macrocarpa (Pm) known as mahkota dewa (In West Sumatra), Melastoma malabathricum (Mm) known as sikaduduak and Morinda citrifolia (Mc) known as mengkudu. The three types of plants can grow wild anywhere in West Sumatra and found many.

Phaleria macrocarpa (Scheff.) Boerl (Thymelaceae) is commonly known as crown of god, mahkota dewa, and pau. It originated from Papua Island, Indonesia and it grows in tropical areas. This plant is one the of most popular medicinal plants in Indonesia. Pm grows throughout the year in tropical areas reaching a height of around 1-6 m. It is a complete tree (stem, leaves, flower and fruit) and the fruit shape is eclipse with a diameter of around $3 \mathrm{~cm}$. The color of the fruit is green before ripening and red when fully ripe [8]. Traditionally, $\mathrm{Pm}$ has been used to control cancer, impotency, hemorrhoids, diabetes mellitus, allergies, liver and heart disease, kidney disorders, blood diseases, acne, stroke, migraine, and various skin diseases [9].

This wild shrub belongs to the family of Melastomataceae and can be found growing in various parts. [10]. Melastoma, well-known as 'senduduk' among the local folks, can grow up to 13 feet high in the tropics and remains perennially evergreen [11]. The most recent research on $\mathrm{Mm}$ revealed that its bioactive constituents exhibited free radical scavenging activity and anti-inflammatory effects on mouse ear edema [12].

$M c$ is an evergreen or small tree that grows in many tropical regions of the world. The fruit of this tree has a history of use as both food and medicine among Pacific Islanders and in Southeast Asia [13],[14]. Several reports have described various potential health benefits of noni fruit , including immunomodulation and antioxidant activities in vitro and in vivo [15].

The objective of this research project is to study the antioxidant activity of three unique plants from Indonesia used for medicine. Pm is usually consumed as a dry fruit for beverage, the extract of Mm leaf and the extract of Mc fruit and leaves are used interchangeably in traditional medicine for their antioxidant properties. However, there is a lack of scientific evidence about the safety and efficacy of Pm, Mm and Mc use for medicinal purposes.

\section{MATERIAL AND METHOD}

\section{A. Material}

The dried Pm fruit, the extract of MM leaf and Mc fruit.

\section{B. Extraction Process}

Fruit of $\mathrm{Pm}$ and leaf sikaduduak were extract with maceration processing by using $99.6 \%$ ethanol with a ratio of 1:1. After extraction, each extract evaporated with vacuum evaporator at a temperature of $40 \mathrm{C}$ for 1 hour.

\section{Preparation of Dried Extract}

Fruit of Phaleria, Mc and leaf of Mm were dried in oven and powdered.

\section{The antioxidant method}

The antioxidant activity of the dried fruit of $\mathrm{Pm}$, the extract of $\mathrm{Mm}$ leaf and the extract of Mc fruit will be determined using the DPPH method. The method established by Tagashira and Ohtake (1998) was used with slight modification. Powder extracts of $\mathrm{Mm}, \mathrm{Pc}$ and $\mathrm{Mc}$ were prepared at $2 \mathrm{mg} / \mathrm{L}, 1 \mathrm{mg} / \mathrm{L}, 0.5 \mathrm{mg} / \mathrm{L}, 0,25 \mathrm{mg} / \mathrm{L}, 0,125 \mathrm{mg} / \mathrm{L}$ and $6,25 \mathrm{mg} / \mathrm{L}$ in methanol. Ethanol extract of $\mathrm{Mm}, \mathrm{Pm}$ and Mc were prepared at $10 \mathrm{mg} / \mathrm{L}, 5 \mathrm{mg} / \mathrm{L}, 2,5 \mathrm{mg} / \mathrm{L}, 1,25 \mathrm{mg} / \mathrm{L}$, $0,625 \mathrm{mg} / \mathrm{L}, 0,3125 \mathrm{mg} / \mathrm{L}$ and $0,15625 \mathrm{mg} / \mathrm{L}$ in methanol. A test sample solution was added to $3,8 \mathrm{~mL}$ of $50 \mu \mathrm{M}$ DPPH methanolic solution. After fortexing, the mixture was incubated for 30 minutes at room temperature. The changes of DPPH in color were measured at $517 \mathrm{~nm}$. The differences in absorbance between a test sample and a control was expressed as DPPH radical Scavenging Activity.

The percentage was calculated by the following formula:

$$
\mathrm{y}=\frac{\text { Abs Control }- \text { Abs sample }}{\text { Abs control }} \times 100
$$$$
\text { Percentage of DPPH Radical Scavenging Activity }
$$

\section{E. Total polyphenol}

A $1 \mathrm{ml}$ of extract was transferred to a test tube and orderly added $1 \mathrm{ml}$ of $95 \%$ ethanol and $5 \mathrm{ml}$ istilled water. $0.5 \mathrm{ml}$ $(50 \%)$ of Folin-Ciocalteu solution reagent was added to each sample. After 5 minutes, $1 \mathrm{ml}$ of $5 \% \mathrm{Na} 2 \mathrm{CO} 3$ was added, the samples were mixed and allowed to stand $1 \mathrm{~h}$ in darkness and absorbance were measured at $760 \mathrm{~nm}$, against $95 \%$ ethanol as blank. Total polyphenol content were standardized against gallic acid and expressed as micrograms phenol/g sample gallic acid equivalen (GAE).

\section{RESULT AND DISCUSSION}

\section{A. Percentage of Extract}

The three exotic plants we prepared in two forms, dried fruit or leaf and extract in ethanol. We have obtained the results as shown in Figures 1 and 2. Medicine from natural resources are very important, because syntehtic medicine could be harmfull to human health. Pm (Phaleria macrocarpa), Mc (Morinda citrifolia) and Mm (Melastoma malabathricum) are potent source as antioxidant.

PPm (Powder of Phaleria macrocarpa), PMc (Powder of Morinda citrifolia), PMm (Powder of Melastoma malabathricum),

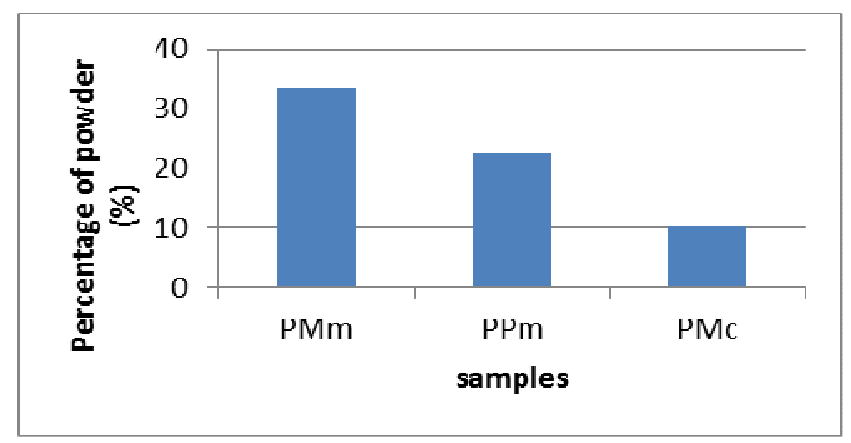

Fig. 1. Powder percentage of dried fruit and leaf of Pm, Mc and Mm. 
Figure 1 showed that $\mathrm{Mm}$ have the highest percentage of powder. It depend on the water content content of the leaf. While the fruit of Mc, as a fruit have amount of water content. The use of dried leaf or fruit become common because the effectiveness to consume. The process was very simple, first dried the leaf or fruit then dried

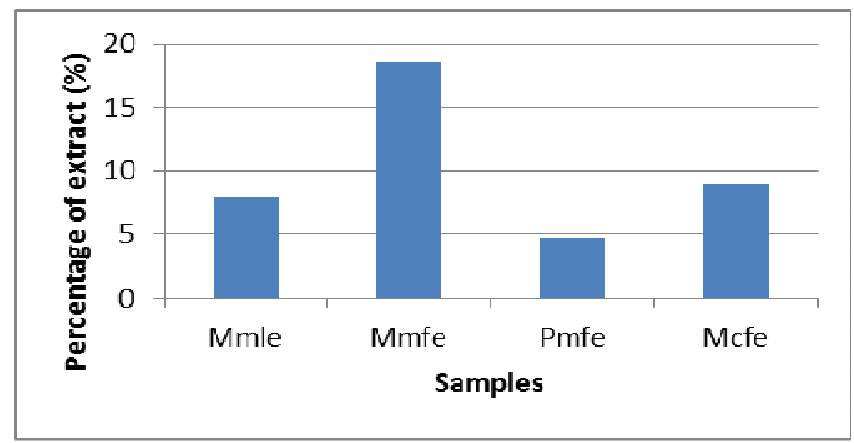

Fig. 2. The ethanol extract percentage of Pmfe (Phaleria macrocarpa fruit extract), Mcfe (Morinda citrifolia fruit extract), Mmle (Melastoma malabathricum leaf extract) and Mmf (Melastoma malabathricum fruit).

We measure leaf and fruit of $\mathrm{Mm}$, and the result showed fruit have more high percentage in ethanol extract. Figure 2 showed that the use of ethanol can extract the bioactive compound from leaf and fruit.

\section{B. DPPH Radical Scavenging Activity}

The antioxidant activity measured by using DPPH as the radical solution. The result of antioxidant activity of PPm, PMc and PMm showed from Figure 2.

The antioxidant activity were measured by using DPPH as a stable free radical. The radical scavenging activity of the organic compound DPPH is considered a good in vitro model that is widely used to assess antioxidant efficacy within a very short time. In its radical form, DPPH disappears upon reduction by an antioxidant compound or a stable diamagnetic molecule, resulting in a color change from purple to yellow, which could be taken as an indication of the hydrogen-donating ability of the tested samples [16]. Concentration played an important for measurement. Figure 3 showed that Pmm and PPm were have very high antioxidant. The concentration $2 \mathrm{mg} / \mathrm{L}-0.5 \mathrm{mg} / \mathrm{L}$ cannot be used for measurement because of very high antioxidant concentration. Started from $0,125 \mathrm{mg} / \mathrm{L}$ for $\mathrm{PMm}$ and $0,25 \mathrm{mg} / \mathrm{L}$ for PPm can be used for antioxidant measurement with DPPH. Pmc have the lowest antioxidant activity compared with PMm and PPm. PMm have the highest antioxidant among others. Mm extract is safe even at a high dose of $5 \mathrm{mg} / \mathrm{Kg}$ and has no oral toxicity. It was found that $\mathrm{Mm}$ suggest the exellent medicinal bioactivity and explain the popularity as folk medicine [17].

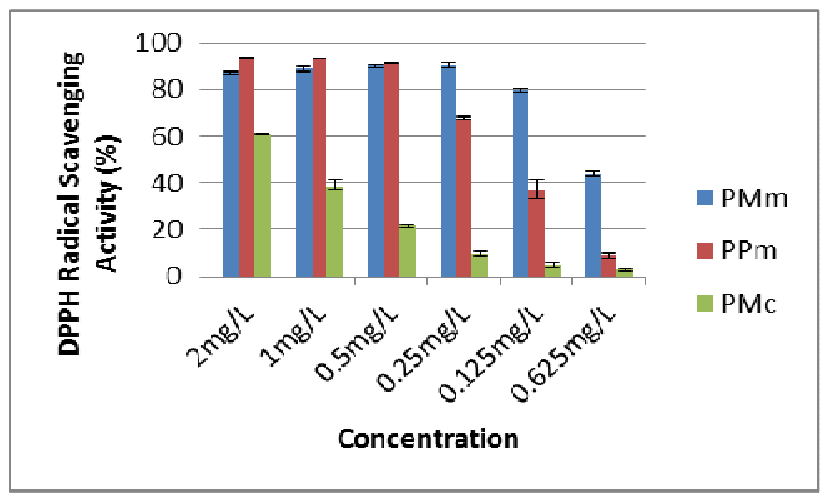

Fig.3. Dpph Radical scavenging activity of PPm (Powder of Phaleria macrocarpa), PMc (Powder of Morinda citrifolia), PMm (Powder of Melastoma malabathricum). I : Standard deviation of triplicate.

Compared three kinds of the unique plants $\mathrm{Mm}$ have the greatest pontentioal as antioxidant than Pm and Mc. Mc have the lowest antioxidant activity among others.

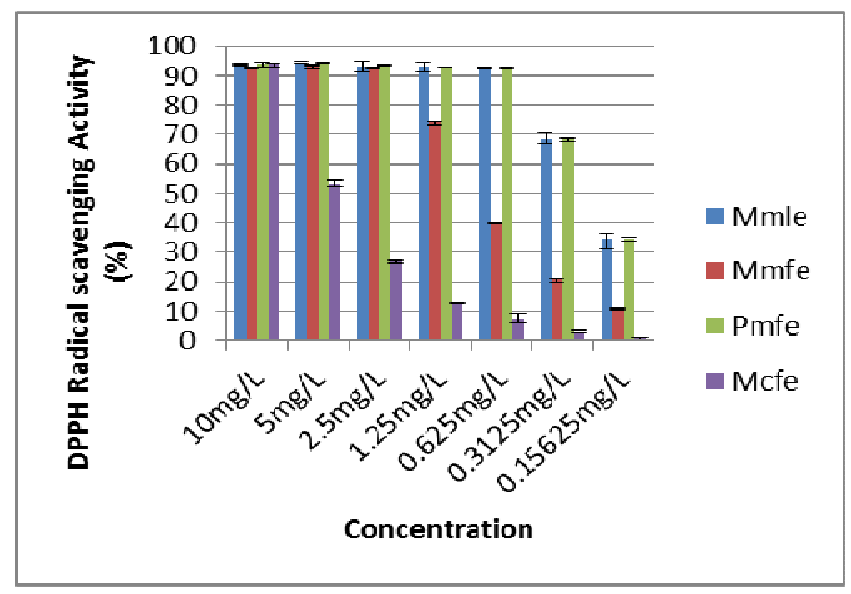

Fig.4. Dpph Radical scavenging activity of Pmfe (Phaleria macrocarpa fruit extract), Mcfe (Morinda citrifolia fruit extract), Mmle (Melastoma malabathricum leaf extract) and Mmf (Melastoma malabathricum fruit) I : Standard deviation of triplicate.

The same result with the dried fruit of $\mathrm{Pm}, \mathrm{Mc}$ and $\mathrm{Mm}$ leaf extract, $\mathrm{Mm}$ was the highest antioxidant activity. Because the concentare in a very high concentration, the measurement for antioxidant begin from $0,3125 \mathrm{mg} / \mathrm{L}$ for $\mathrm{MM}$ and PM. Concentration $5 \mathrm{mg} / \mathrm{L}$ for $\mathrm{Mc}$ for antioxidant measurement withg DPPH methods.

Unmature white hard Mc had ORAC values of 1880 $\mu \mathrm{Mol}$ Trolox, total phenols of $285 \mathrm{mg}$ gallic acid and ascorbic acid of $224 \mathrm{mg}$ per $100 \mathrm{~g}$. Matured white hard Mc have high antioxidant capacity, total phenols and ascorbic acid content. [18]. According to Kamiya [19], pontent antioxidants from noni fruits are neolignan, americanin A, 3,3'-bisdemethylpinoresinol, morindolin and isoprincepin. 


\section{Total Polyphenol}

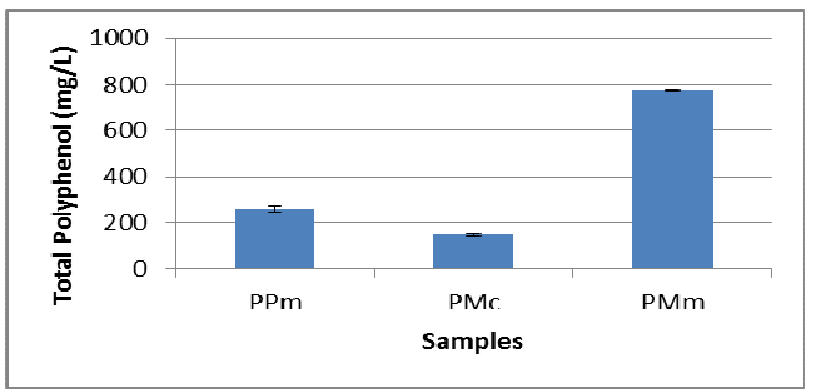

Fig. 5. Total Polyphenol of PPm (Powder of Phaleria macrocarpa), PMc (Powder of Morinda citrifolia), PMm (Powder of Melastoma malabathricum). I : Standard deviation of triplicate.

Figure 6 showed that the dried leaf of $\mathrm{Mm}$ have the highest polyphenol. Interestingly dried fruit of Pm have total polyphenol three times low than dried leaf of $\mathrm{Mm}$, which means, there is another compounds act as antioxidant besides polyphenol. The compound must be very reactive with oxygen or easily to oxidated, as shown in Figure 6, total polyphenol of Pmfe not so differ with Mmle. Quercetin was found to be the most active as radical scavenger in DPPH method with $\mathrm{IC}_{50}$ of $0,69 \mu \mathrm{M}$. $\alpha$-Amyrin and kaempherol-3O-(2', 6"'-diO-p-trans-coumarol) glycoside demonstrated the strongest activities in the anti-inflammatory assay of TPA mouse ear oedema with $\mathrm{IC}_{50}$ of 0,11 and $0,31 \mathrm{mM} / \mathrm{ear}$ respectively in $\mathrm{Mm}$ [12].

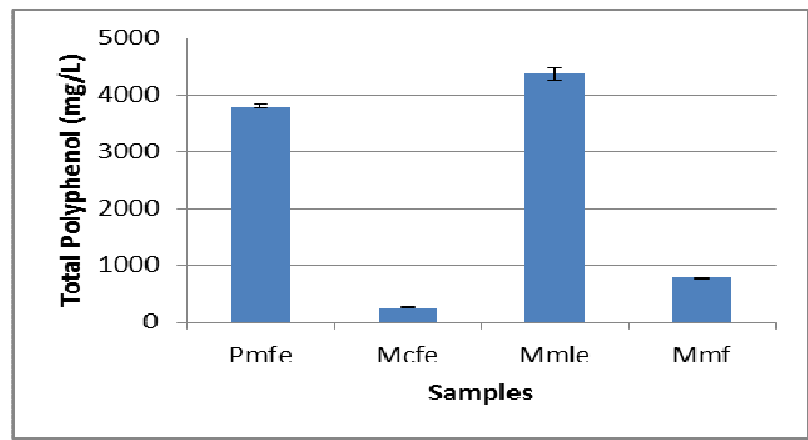

Fig. 6. Total Polyphenol of Pmfe (Phaleria macrocarpa fruit extract), Mcfe (Morinda citrifolia fruit extract), Mmle (Melastoma malabathricum leaf extract) and Mmf (Melastoma malabathricum fruit) I : Standard deviation of triplicate.

Some compounds successfully isolated from Mm by using spectroscopic techniques, resulted in the isolation of a series of flavonoids, triterpernoids and alkaloids. These compounds are $\alpha$-amyrin, patriscabratine, auranamide, quercetin, quercitrin and kaempherol-3-O-(2', 6' '-diO-p-transcoumarol) glycoside [12],[20]. The major flavonoid compounds in Pm were kaemferol, myricetin, naringin and rutin [21].

\section{CONCLUSIONS}

The kinds of the unique plant of Indonesia Phaleria macrocarpa, Morinda citrifolia and Melastoma malabathricum were the potent antioxidant. Interestingly
Melastoma malabathricum leaf have the highest antioxidant activity and polyphenol compared to others.

\section{ACKNOWLEDGMENT}

The authors thanks to The Australia Indonesia Institute For Humanity And Development (AIIRHID), Deakin University Australia and Andalas University Indonesia for funding this research study.

\section{REFERENCES}

[1] Szabo. M. R., Iditoiu. C., Chambre. D and Lupea. A. X. 2007. Improved DPPH Determination for antioxidant activity spectrophotometric assay. Institute of Chemistry, Slovak Academy of Sciences.

[2] Halliwell. B., Aeschbach. R., Loliger. J and Aruoma. O. I. 1995. The characterization of antioxidants. Food Chem. Toxicol. 33, 601.

[3] Kanter , M. 1998. Free radicals, exercise and antioxidant supplementation. Proc Nutr Soc. 57 : 9-13.

[4] Meydani, M., Lipman, R, D., and Han, S, N. 1998. The effect of long-term dietary supplementation with antioxidants. Ann NY acad Sci. 854: 352-360.

[5] Pospisil, J and Klemchuk, P. P. 1990. Oxidation Inhibition in Organic Materials, vol I. CRC Press, Inc, Boca Raton, Fla.

[6] Pokorny, Jan., Ysnishlieve, Nedyalka and Gordon, Michael. 2001. Antioxidants in Food. Practical application.CRC Press. Woodhead Publishing Limited. Cambridge England.

[7] Cook. N. C., Samman. S. 1996. Flavonoids-Chemistry, metabolism, cardioprotective effects and dietary sources. Nutr. Biochem.7 : 66-79

[8] Backer C, van den Brink R: Flora of Java (Spermatophytes Only), vol. II. Noordhoff, Groningen, the Netherlands; 1965.

[9] Zhang Y, Xu X, Liu H: Chemical constituents from Mahkota Dewa. Journal of Asian Natural Products Research 2006, 8:119-123.

[10] Whitmore TC (1972). Tree flora of Malaya., Vol. 1. Kuala Lumpur: Longman.

[11] Susanti D, Sirat HM, Ahmad F, Mat Ali R, Aimi N, Kitajima M (2007). Antioxidant and cytotoxic flavonoids from the flowers of Melastoma malabathricum L. Food Chem., 103: 710-716.

[12] Susanti, D.; Sirat, H.M.; Ahmad, F.; Ali, R.M. 2008. Bioactive constituents from the leaves of Melastoma malabathricum L. Jurnal Ilmiah Farmasi 5, 1-8.

[13] Morton J: The ocean-going Noni, or Indian Mulberry (Morinda citrifolia, Rubiaceae) and some of its "colorful" relatives. Econ Bot 1992, 46:241-256.

[14] West BJ, Jensen CJ, Westendorf J, White LD: A Safety Review of Noni Fruit Juice. J Food Sci 2006, 71:R100-R106.

[15] Wang MY, Su C: Cancer preventive effect of Morinda citrifolia (Noni). Ann NY Acad Sci 2001, 952:161-168.

[16] Lee, Y.R., Woo, K.S., Kim, K.J., Song, J.R., and Jeong, H.S. 2007. Antioxidant activities of ethanol extracts from germinated specialty rough rice. Food Sci Biotechnol. 16 : 765-770.

[17] Alnajar ZAAM, Abdulla MA, Ali HM, Alshawsh and Hadi AHA. 2012. Acute Toxicity Evaluation, Antibacterial, Antioxidant and Immunomodulatory Effects of Melastoma malabathricum. Molecules. 17, 3547-3559.

[18] Yang J, Gadi R and Thomson T. 2011. Antioxidant Capacity, Total Phenols and Ascorcic acid Content of Noni (Morinda citrifolia) Fruits and Leaves at Various Stages of Maturity. Micronesica 41 (2); 167-176.

[19] Kamiya K, Tanaka H, Endang, Umar and Satake. 2004. Chemical Constituents of Morinda citrifolia Fruits Inhibit Copper-Induced Low Density Lipoprotein Oxidation. Journal of Agriculture and Food Chemistry 52 . 5843-5848.

[20] Sirat HM, Susanti D, Ahmad F, Takayama H, Kitajima M. 2010. Amides, Triterpene and Flavonoids From The Leaves of Melastoma malabathricum L. Journal of Natural Medicines. Vol 64, Issue 4, pp 492-495.

[21] Hendra R, Ahmad S, Sukari A, Shukor MY and Oskoueian E. 2011. Flavonoid Analyses and Antiomicrobial activity of Various Parts of Phaleria macrocarpa (Scheff.) Boerl Fruit. Int. J. Mol Sci. 12, 34223431. 